\title{
FRANZ KAFKA Y FEDERICO GARCÍA LORCA: EL DESAPARECIDO POETA EN NUEVA YORK
}

\author{
Franz Kafka and Federico García Lorca: The missing poet in New York
}

\author{
Yislén Barboza Hidalgo*
}

\begin{abstract}
RESUMEN
Tanto Franz Kafka como Federico García Lorca han sido vasta e individualmente investigados, mas no con una comparación académica entre sus obras. Por esta razón, en este artículo se analizarán los puntos convergentes entre estos dos escritores europeos, con la idea de enriquecer la crítica literaria, tanto la de Kafka como la de García Lorca. Se procederá entonces al paralelismo por temas: la ciudad, la visión negativa de Nueva York, las imágenes grotescas, la deshumanización producto del capitalismo estadounidense, el extrañamiento que ambos escritores provocan en sus lectores y la percepción del arte que ambos comparten. Una vez llevada a cabo la comparación entre América (Kafka) y Poeta en Nueva York (García Lorca), y si se dejan de lado las particularidades propias de cada uno de estos autores, se comprueba que sus textos comparten mucho en común. Además, se concluye que Kafka y García Lorca fueron artistas apasionados por su labor, porque en la producción literaria ellos encontraron la satisfacción que el mundo alrededor suyo no les ofrecía.
\end{abstract}

Palabras clave: la ciudad, imágenes grotescas, la deshumanización, Nueva York, extrañamiento.

\begin{abstract}
Both Franz Kafka and Federico Garcia Lorca have been vastly and individually investigated, but not with an academic comparison between their works. For this reason, in this article the converging points between these two European writers will be discussed, with the idea of enriching the literary criticism for both Kafka and Garcia Lorca. It will then proceed to compare the texts by topics: the city, the negative view of New York, grotesque images, the dehumanization as product of the American capitalism, the feeling of strangeness that both writers provoke in the readers, and the perception of art shared by both authors. Once the comparison between América (Kafka) and Poeta en Nueva York (García Lorca) is carried out, and if the particularities of each of these authors are not considered, it is found that their texts share many commonalities. In addition, it is concluded that Kafka and García Lorca were passionate artists about their work, because they found in literary production the satisfaction that the world did not offer them.
\end{abstract}

Key Words: the city, grotesque images, dehumanization, New York, strangeness.

Universidad de Costa Rica. Bachiller en Filología Española y estudiante de Maestría Académica en Lingüística. Costa Rica. Correo electrónico: yislen.barboza@gmail.com

Recepción: 30/8/16. Aceptación: 11/10/16. 


\section{Introducción}

Durante los primeros años del siglo XX, Europa fue testigo de grandes cambios en su realidad, puesto que varias de sus potencias iban perdiendo terreno en América (España, Inglaterra) y Estados Unidos iba adquiriendo fuerza. Asimismo, las máquinas con sus motores se iban abriendo paso en lo que se pensaba constituiría la formación de una sociedad más competitiva. El ser humano pasó a ser un objeto reemplazable y su valor se medía con respecto a su desempeño en el avance hacia grandes capitales. A consecuencia de estos cambios, la incertidumbre y la desesperanza en los corazones de la humanidad alcanzaron grados inimaginables, porque no se vislumbraba una luz optimista de salvación en un futuro cercano.

El pesimismo y la desesperación europeos irían en aumento conforme se adentraba en el siglo. Sin embargo, un halo esperanzador cubría a los Estados Unidos y al continente americano, al otro lado del Atlántico, con el mito todavía vivo del oro de la conquista y la ilusión de tierras inacabables a la orden de quien las quisiese trabajar, y la posibilidad de llegar a ser alguien con un inmenso capital. Esta promesa de adueñarse de un pedazo de tierra y de tener un futuro mejor, fue la invitación que tentó (y sigue tentando) a miles de europeos, quienes suben al barco atraídos por este faro con la forma de la Estatua de la Libertad.

Este sueño americano se ha visto reflejado en la literatura, tanto en escritores europeos como en los del continente americano. Durante el siglo XX, Nueva York se convertiría entonces en la ciudad en donde se encontraría el paraíso para todos aquellos quienes desearan superarse, fuera esta ilusión la de llegar a ser un gran artista (piénsese en Broadway), un gran escritor o un acaudalado empresario. Pero no todo lo que brilla es oro, porque siempre hay un precio que pagar por lo que se ambiciona, o al menos de esta manera lo perciben escritores como Franz Kafka (1883-1924) y Federico García Lorca (1898-1936), quienes tradujeron el caos y la desesperación en obras literarias para la posterioridad. Estos dos literatos, tan distintos, no solo en su estilo como en su lengua, comparten similitudes difíciles de pasar por alto.

Es por esto que el propósito de este ensayo es demostrar los puntos de convergencia que los escritores Franz Kafka y Federico García Lorca comparten cuando describen pictóricamente la ciudad de Nueva York y en cómo ambos recurren a elementos grotescos para criticar la deshumanización que el capitalismo estadounidense ha provocado en sus habitantes. Más en detalle, se comparará la novela América (Kafka, 2013) con Poeta en Nueva York (García Lorca, 1987), en particular con los poemas "Danza de la muerte", "Paisaje de la multitud que vomita (Anochecer de Coney Island)", "Paisaje de la multitud que orina (Nocturno de Battery Place)", "Ciudad sin sueño (Nocturno del Brooklyn Bridge)", "La aurora" y "Nueva York (Oficina y denuncia)".

\section{Justificación}

La justificación de esta investigación se basa en que, a pesar de que ambos escritores son reconocidos y estudiados mundialmente, no se han realizado estudios comparativos que examinen las similitudes en las imágenes que estos dos europeos emplean para describir y criticar a Nueva York con su sociedad capitalista. Quizá se deba al hecho de que al poemario de García Lorca se le considere de un estilo oscuro y de difícil comprensión, que provoca acercamiento y distanciamiento al lector, por su vaivén entre la claridad y la opacidad de sus imágenes (McKinlay, 2001), las cuales han sido examinadas principalmente desde el surrealismo. En el caso de América o El desaparecido de Kafka, si bien los surrealistas aprecian el absurdo kafkiano (Grosu, 2010), los estudios han versado más en las aventuras o desventuras del personaje Karl Rossmann y a su crítica sociocultural (Payne, 1997). En fin, tanto Kafka como García Lorca han sido vastamente investigados, mas no en una comparación académica entre sus obras.

A causa de la falta de un puente que acerque a estos dos autores, la metodología que 
se utilizará para este estudio es la comparatística, en donde se analizarán los puntos convergentes entre estos dos europeos, con la idea de enriquecer la crítica literaria, tanto la de Kafka como la de García Lorca. Así, en primer lugar, se revisará brevemente el contexto histórico de Estados Unidos, especialmente en Nueva York a inicios de 1900. En segundo lugar, se procederá con la comparación por temas: la ciudad, la visión negativa de Nueva York, las imágenes grotescas, la deshumanización producto del capitalismo estadounidense, el extrañamiento que ambos escritores provocan a sus lectores y la percepción del arte que ambos comparten.

\section{Comparación de los textos}

Procediendo al análisis, cabe mencionar que para inicios del siglo XX, y en concordancia con Aurora Bosch (2005), Estados Unidos se había convertido en una potencia económica mundial, producto de la industrialización posterior a la Guerra Civil, y de la gran oleada migratoria de alrededor de unos 23.5 millones de inmigrantes, principalmente del sur y este europeo. Nueva York fue parte de esas transformaciones drásticas, ya que adquirió la posición de autoridad económica con la creación de Wall Street y la Bolsa de Valores de Nueva York. Se erigió como la ciudad soñada y temida de la estética y del cosmopolitismo. Sus límites físicos se fueron extendiendo a sus anchas y a pasos agigantados, con el incremento excesivo en la construcción de rascacielos (McMullan, 1996).

\subsection{La ciudad y su visión negativa}

En cuanto a la ciudad como tema, José Ortega López (1997) explica que ha sido considerada como un elemento amenazador desde el siglo XVIII, cuando la urbe pasó a ser el centro lógico de la civilización y ocasionó la ruptura del hombre con su entorno físicoespiritual. Esta visión negativa de la ciudad se prolongó hasta el siglo XX (periodo pertinente para esta investigación) y provocó que muchos escritores de ese momento elaboraran un tipo de literatura en donde el rechazo hacia la urbanización y al enajenamiento que sufre el ser humano (dentro del ajetreo citadino) se traduzcan por medio de imágenes y simbolismos. A esto se refiere María Clementa Millán (1987) cuando explica que la visión de la gran urbe como signo de progreso, anteriormente alabada por los ultraístas y creacionistas, deja de serlo a finales de los años 20 para ser reemplazada por una consideración de tono negativa, la cual ve en la metrópolis un mundo que destruye los valores humanos y que, por lo tanto, es adverso para el hombre.

Para Federico García Lorca y Franz Kafka, Nueva York constituía una metonimia de los vicios de la vida cosmopolita y capitalista, sea en Norteamérica o en cualquier otro lugar. Pero, a diferencia de Lorca que sí la visitó y que para él representa el caos (Chaves Bustos, 2007), Kafka nunca salió de Europa. Sus conocimientos sobre esta ciudad se basaron en conversaciones y en fotografías que interpretaba y, de acuerdo con Kenneth Payne (1997), las representaciones de las escenas y situaciones americanas de Kafka fueron más un ejercicio de imaginación creativa que reproducciones miméticas convencionales de la actualidad. De esta manera, son imágenes de su entorno real, en Praga, pero remodeladas drásticamente para ambientarlas en Nueva York; porque según Pulitzer (citado por Payne, 1997: 30): "it is as if Karl's story could have taken place anywhere, as if its American setting is purely incidental."

Indiferentemente de si se trata o no de basar sus historias en Nueva York, Kafka y García Lorca comparten similitudes en las imágenes con las cuales describen esta ciudad. Considérese cuando Karl Rossmann, el personaje principal de América, se detiene en el balcón de su habitación, a seis pisos de altura, para observar el paisaje que este contrasta significativamente con el de su país natal en Europa, porque allá no habría encontrado nada similar a los distintivos rascacielos neoyorquinos. A ellos hace referencia el narrador cuando dice que "aquí sólo permitía la visión de apenas una calle -que corría recta, $\mathrm{y}$ por eso como en una suerte de fuga, entre 
dos filas de casas verdaderamente cortadas a plomo-" (Kafka, 2013: 46) (itálica para propósitos de este ensayo), porque estas filas de casas simbolizan los rascacielos, su verticalidad se destaca ("cortadas a plomo") ante una calle en donde no se puede observar nada más en la lejanía, porque las altas paredes de los edificios bloquean el panorama. Incluso la luz es afectada por los reflejos en los cristales de las ventanas; la cual, según el narrador, es "llevada lejos por ellos y traída cuidadosamente otra vez, y que para el ojo embelesado cobraba una corporeidad intensa, como si a cada momento, en infinitas repeticiones, alguien estrellase con toda fuerza, sobre esa calle, un cristal que cubriera todas las cosas" (Kafka, 2013: 46).

De manera similar, García Lorca alude a esta ciudad en su poema "La aurora", porque remite a una visión panorámica, en donde él dibuja los contornos que observa: "La Aurora de Nueva York tiene / cuatro columnas de cieno" (1987: 161), en donde las cuatro columnas de cieno representan los rascacielos, que en la hora del albor se observan oscurecidos por las sombras que quedan de la noche. Asimismo, la imagen del tamaño de los edificios se percibe cuando la voz poética dice que "La aurora de Nueva York gime / por las inmensas escaleras" (1987: 161), por cuanto las escaleras simbolizan la altura de las construcciones y que por su elevación, impide el contacto de la luz del sol con las calles: "La aurora llega y nadie la recibe en su boca / porque allí no hay mañana ni esperanza posible" (1987: 161). Aquí, "mañana" puede ser interpretado, como el tiempo cuando la luz aún es pura, antes de iniciar el día (Chevalier y Gheerbrant, 1986) o como la promesa del tiempo venidero (Real Academia Española, 2015). Tomando cualquiera de las dos acepciones, la luz no fluye por las calles de Nueva York como se verá más adelante.

En este mismo poema, la voz poética observa a los transeúntes que caminan abajo, en la calle, a los cuales él llama "las monedas en enjambres furiosos" (1987: 161), por la semejanza entre una moneda y un sombrero visto desde arriba, y porque los enjambres representan las multitudes de personas en movimiento constante. Kafka también dibuja en su novela un cuadro similar al de Lorca cuando Karl sale a su balcón: "esa calle se agitaba con un tráfico siempre apresurado que, visto desde arriba, parecía una confusa mezcla en la que hubieran derramado esbozos siempre nuevos de figuras humanas y de techos de vehículos de toda especie" (2013: 46). Ambos autores, a través de sus personajes, dan cuenta de la "confusa mezcla" y del "enjambre" de personas que transitan las calles de Nueva York, y da la impresión, aunque no es posible por su muerte en 1924, de que para redactar su novela Kafka estuviera viendo las mismas fotografías que García Lorca incluyó en su poemario entre 1929 y 1930.

Otra escena que Kafka relata sobre la ciudad, desde las aceras, es aquella cuando Karl intenta escapar del Hotel Occidental, cuando dice que: “(...) cruzaba el automóvil una de esas avenidas que parecen verdaderas plazas, aparecían (...) las aceras colmadas por una multitud que avanzaba a pasos minúsculos y cuyo canto era más monocordio que el de una sola voz humana" (2013: 57). En este pasaje, la multitud remite a la cantidad de personas que transitan las aceras de Nueva York, la cual es comparable con la imagen que narra Lorca en su poema "Paisaje de la multitud que vomita (Anochecer en Coney Island)", cuando la voz poética habla de una mujer gorda.

Conviene citar un fragmento del poema de Lorca para demostrar la semejanza entre ambos textos: "La mujer gorda, enemiga de la luna, / corría por las calles y los pisos deshabitados" (1987: 143). La mujer gorda es la multitud que corre por las calles, similar a la que Kafka imagina, la cual se mueve incesantemente, siempre hacia adelante y que, por ser tantos los caminantes e ir hombro con hombro, la luz del sol no llega a la acera: “(...) y filtraba un ansia de luz en las circulaciones subterráneas" (1987: 143). Esta imagen de la muchedumbre en movimiento es característica de una sociedad que lleva prisa, que no se detiene ante nada, que debe esforzarse para mantener su condición de vida: sea esta la de hacer más dinero a través de otros, o la de sobrevivir bajo la opresión de quienes se llevan el dinero. 


\subsection{Las imágenes grotescas}

Detrás de estas descripciones físicas de la ciudad, se esconde una visión negativa representada por medio de las imágenes ya estudiadas y por otras más grotescas, presentes en ambos textos. Es posible que este aspecto grotesco sea especialmente distinguible en Poeta en Nueva York, por el léxico utilizado, como se aprecia en los títulos de dos de sus poemas: "Paisaje de la multitud que vomita (Anochecer de Coney Island)" y "Paisaje de la multitud que orina (Nocturno de Battery Place)", en donde se hace referencia a elementos de orden escatológico como 'vomitar', 'orinar' y a la demasía. La mujer gorda recuerda a quien come sin llenarse, a quien se goza en el carnaval de los excesos, porque en Lorca, ella "levantaba las furias de los banquetes de los siglos últimos / y llamaba al demonio del pan por las colinas del cielo barrido" (1987: 143). Esta mujer es la multitud que, como apunta José Antonio Llera (2011), es la opulencia de la cultura estadounidense reflejando el capitalismo, este que fuerza a las masas a caer en el consumismo que enferma a la sociedad: es quien "empuja en la garganta" a "los muertos, los faisanes y las manzanas de otra hora" (García Lorca, 1987: 143).

En cuanto a la novela de Kafka, hay tres personajes que se asemejan a esta "mujer gorda": Green, Pollunder y Brunelda. Cuando Karl Rossmann se encuentra con ellos, no deja de sorprenderse por su tamaño. Su volumen les recuerda, a Karl y a los lectores, los excesos grotescos de un cuerpo acostumbrado a satisfacer sus placeres; porque estos tres personajes representan el consumismo y el enriquecimiento a costa de otros, a quienes Kafka critica. Green y Pollunder son hombres adinerados, empresarios acostumbrados a explotar a otros hombres más bajos en la escala del éxito (como a Karl y a otros inmigrantes) y que en su mundo, opuesto al de Karl, el hambre está más que sobresatisfecha. Por esta razón, las proporciones y el comportamiento del señor Green le provocan a Karl náuseas y repulsión, porque su "apetito voraz y locuacidad incontenible" (Víquez Jiménez, 2012: 103) se traducen en elementos grotescos: la manera en como devora su cena desconciertan a Karl y al lector.

Green y Pollunder son comparables con los hombres a quienes García Lorca critica en su poema "Danza de la muerte":

\footnotetext{
Pero no son los muertos los que bailan.

Estoy seguro.

Los muertos están embebidos devorando sus propias manos.

Sonlosotroslosquebailanconelmascarónysuvihuela; son los otros, los borrachos de plata, los hombres fríos, los que crecen en el cruce de los muslosy llamas duras, losque buscan la lombrizen el paisaje de las escaleras, los que beben en el banco lágrimas de niña muerta o los que comen por las esquinas diminutas pirámides del alba. (1987: 139-140)
}

Son estos "hombres fríos", "borrachos de plata" a quienes Lorca ataca con su advertencia sobre la danza de la muerte: "los que beben en el banco lágrimas de niña muerta / o los que comen por las esquinas diminutas pirámides del alba"; la cual no los dejará bailar más en sus excesos: "iQue no baile el Papa! / ¡No, que no baile el Papa! / Ni el Rey, / ni el millonario de dientes azules" (1987: 140). Esta censura se compara, en la novela de Kafka, con la de Brunelda: esta mujer gorda que ha perdido ya su baile, porque es una adinerada cantante venida a menos quien, para Delamarche y Robinson, es todavía una dama refinada que les satisface el hambre y/o sus necesidades sensuales (físicas para Delamarche, pues duerme con ella; pero eróticas para Robinson, que solo la admira y la desea): "Brunelda es toda ella un cuerpo voluminoso y al mismo tiempo deseable", como se expresa de ella Alí Víquez Jiménez (2012: 107). Pero es, en realidad, una mujer que causa repugnancia por su "cuerpo excesivamente obeso" (Kafka, 2013: 186) y por los bochornos que ella sufre, los cuales se pueden relacionar con su avanzada edad y con su estado de decadencia, porque ella no puede valerse más por sí misma, va dejando de bailar por sus excesos estomáquicos.

Otro aspecto que comparten los dos textos analizados es la imagen grotesca con que representan el derroche excesivo de alimentos en Nueva York. Tanto un autor como el otro describen la enorme cantidad de animales que llevan al 
matadero para satisfacer las necesidades del consumismo en masa. Considérese el siguiente fragmento del poema "Nueva York (Oficina y denuncia)” (García Lorca, 1987: 203-204):

Todos los días se matan en New York

cuatro millones de patos,

cinco millones de cerdos,

dos mil palomas para el gusto de los agonizantes, un millón de vacas,

un millón de corderos

y dos millones de gallos

que dejan los cielos hechos añicos.

Más vale sollozar afilando la navaja

o asesinar a los perros en las alucinantes cacerías

que resistir en la madrugada

los interminables trenes de leche,

los interminables trenes de sangre,

y los trenes de rosas maniatadas

por los comerciantes de perfumes.

Los patos y las palomas

y los cerdos y los corderos

ponen sus gotas de sangre

debajo de las multiplicaciones;

y los terribles alaridos de las vacas estrujadas

llenan de dolor el valle

donde el Hudson se emborracha con aceite.

García Lorca explica gráficamente el sacrificio de sangre que se da en esta ciudad y detalla el tráfico de víveres que se mueve diariamente para sostener el hambre insaciable de los neoyorkinos (piénsese en los personajes mencionados de Kafka), y de los productores que se benefician de este comercio: "los terribles alaridos de las vacas estrujadas" remiten al manejo inadecuado de los animales que son vistos como mercancía y no como seres vivos. La imagen que este poema ofrece es de dolor y de inhumanidad, porque las "multiplicaciones" del capitalismo son lo más importante. Un retrato similar ofrece Kafka cuando narra la partida de Karl hacia las afueras de Nueva York, cuando él iba junto a Delamarche y Robinson "camino a Ramsés". Obsérvese la siguiente cita:

Empezaron luego las caravanas de vehículos que llevaban víveres a Nueva York; avanzaban de modo tan ininterrumpido, en cinco filas que ocupaban todo el ancho del camino, que nadie hubiera podido cruzarlo. (...)

Lo que más sorprendía a Karl era la tranquilidad general. Si no hubiera sido por el griterío de las reses que iban al matadero, quizá no se hubiera advertido más que el golpeteo de los cascos de caballos y el zumbido de los antideslizantes de los automóviles. (...) (2013: 95-96)

La similitud de la imagen que los dos escritores presentan es considerable, porque da la impresión de que están relatando la misma escena: la desproporcionada producción y consumo desfilando por las calles rumbo a la ciudad y, probablemente, hacia el puerto para exportación. Lo más interesante es la particular crítica al capitalismo que Kafka lleva a cabo, porque cuando contrasta su país con Nueva York, lo hace con la intención de resaltar la falta de pequeños productores, quienes no tienen oportunidad de competir contra las grandes compañías que se apoderan del mercado: "No había peatones ni iban hacia la ciudad vendedoras de feria, verduleras, como allá en el país de Karl" (2013: 95-96).

\subsection{La deshumanización como producto del capitalismo}

Tanto Lorca como Kafka subrayan el precio que pagan estos estadounidenses para obtener el sueño americano de ser millonarios y de obtener ganancias. En ambos textos se critica la deshumanización que ocasiona el capitalismo, porque convierte en seres fríos y calculadores a quienes están en el poder; y en personas vacías, sin aspiraciones y sin esperanza a los trabajadores que enriquecen a ese poder. En América, el tío Jacob es un hombre que se maneja bajo el espíritu mercantil, como lo explica Kenneth Payne (1997), porque en su vida no hay lugar para los placeres de la vida y los principios de la eficiencia y de la organización son más importantes para él que crear lazos de afecto con su propio sobrino o con sus empleados. En él no hay misericordia ni segundas oportunidades, porque su corazón ya no alberga humanidad. En el Hotel Occidental, Karl Rossmann también enfrenta el mismo tipo de trato, el de la tiranía sin compasión para quienes no sigan la obediencia y la conformidad del régimen autoritario capitalista (Payne, 1997). Allí, los ascensoristas eran objetos reemplazables, a quienes no se les 
perdonaba el menor error, tal y como le ocurrió a Karl: lo despiden a pesar de haber sido un excelente trabajador el resto del tiempo.

Este trato inhumano se aprecia también en el poema de García Lorca llamado "Ciudad sin sueño (Nocturno del Brooklyn Bridge)”:

\author{
No duerme nadie por el cielo. Nadie, nadie. \\ No duerme nadie. \\ Pero si alguien cierra los ojos, \\ ¡azotadlo, hijos míos, azotadlo! \\ Haya un panorama de ojos abiertos \\ y amargas llagas encendidas. \\ No duerme nadie por el mundo. Nadie, nadie. \\ Ya lo he dicho. \\ No duerme nadie. (1987: 153)
}

En uno de los pocos poemas de este poemario de García Lorca en donde los signos y los significantes son más transparentes, la denuncia que la voz poética lleva cabo es clara: ningún trabajador en los Estados Unidos, en especial en Nueva York, tiene derecho al descanso, porque está obligado a trabajar siempre, sin importar las consecuencias $\mathrm{y}$, de no cumplir con lo ordenado, será expulsado del mundo laboral. Esta inflexibilidad es la que Karl Rossmann experimenta en el hotel y con su tío Jacob. Kafka y Lorca compartieron la percepción de que Nueva York era un mundo "facelessly capitalist, exploitative, meaningless, and dehumanising in the sense of "making impersonal or machine-like" (Allen, 1990: 305; citado por McKinlay, 2001: 157) o la ciudad de la muerte física y / o psicológica, como comenta María Clementa Millán (1987). Así que todos los esfuerzos de quienes quisieran salir adelante no tendrían ni valor ni reconocimiento en un espacio en donde ser un humano dejaba de ser importante.

Otro caso de muerte psicológica, algo diferente a la del Tío Jacob, es la cocinera mayor, una inmigrante europea que ha llegado a donde está por sus propios méritos, pero ha tenido que perder su salud emocional y espiritual porque sufre constantemente de insomnio y de ansiedad. Este insomnio y sobreesfuerzo, sin esperanza de mejorar, está también presente en el poema "La aurora” de García Lorca, cuando dice que:
La aurora llega y nadie la recibe en su boca porque allí no hay mañana ni esperanza posible. A veces las monedas en enjambres furiosos taladran y devoran abandonados niños. Los primeros que salen comprenden con sus huesos que no habrá paraíso ni amores deshojados; saben que van al cieno de números y leyes, a los juegos sin arte, a sudores sin fruto.

La luz es sepultada por cadenas y ruidos en impúdico reto de ciencia sin raíces.

Por los barrios hay gentes que vacilan insomnes como recién salidas de un naufragio de sangre. (1987: 161) (Itálica para efectos de este ensayo)

Varias imágenes en este poema remiten a esa desesperanza por haber perdido el sentido de la vida, porque estas personas, forzadas a trabajar sin descanso y sin misericordia, terminan convirtiéndose en groguis que "vacilan insomnes" por las calles de Nueva York. Es una sociedad que ha dejado de soñar ("devoran abandonados niños") porque consideran que ya "no hay mañana ni esperanza posible". Nada de lo que hagan los satisfará, porque "saben que van al cieno de números y leyes", o sea, al trabajo que no les dará más que "sudores sin fruto". La desesperanza en García Lorca es tangible: para este poeta no hay un futuro prometedor para quienes hayan caído en las garras del capitalismo en Nueva York. En el caso de América, Kafka no es nada esperanzador tampoco. A pesar de que Karl se mantiene en movimiento hacia una mejor calidad de vida, la novela no asegura un final feliz. Cabe destacar que aunque el Gran Teatro de Oklahoma aseguraba trabajo y aceptación para todos, Karl se enfrenta una vez más con lo que Kenneth Payne (1997) llama 'la deshumanización de la fuerza laboral', porque el proceso de contratación dentro de este teatro se rige por un mundo burocrático capitalista similar al de las experiencias anteriores: su imagen va denigrándose gradualmente, de oficina en oficina, hasta llegar al puesto de técnico o, sin eufemismos, el puesto de mano de obra.

En ese mundo oscuro, deshumano e insolidario, no es de extrañarse que los protagonistas de ambos textos se sientan excluidos y alienados. Porque dentro de sus corazones estas actitudes no son aceptables y, 
por lo tanto, sienten que no pueden ser parte de "la multitud" de las masas que se dejan llevar hacia el matadero, como las vacas que ingieren y que luego vomitarán, según Lorca. Apréciese el siguiente segmento de "Paisaje de la multitud que vomita":

\author{
¡Ay de mí! ¡Ay de mí! ¡Ay de mí! \\ Esta mirada mía fue mía, pero ya no es mía. \\ Esta mirada que tiembla desnuda por el alcohol \\ y despide barcos increíbles \\ por las anémonas de los muelles. \\ Me defiendo con esta mirada \\ que mana de las ondas por donde el alba no se \\ atreve. \\ Yo, poeta sin brazos, perdido \\ entre la multitud que vomita, \\ sin caballo efusivo que corte \\ los espesos musgos de mis sienes. (1987: 144)
}

En esta cita, el poeta se siente perdido entre los empujones con que lo arremete la "mujer gorda", o sea, la multitud que se mueve en la sociedad, empujada por el capitalismo. Él se aísla, y desde ahí puede apreciar el sufrimiento de quienes viven en una realidad que deshumaniza y consume a todos, ricos y pobres. Similar sensación padece Karl Rossmann, porque él primero piensa en el bien de los demás, antes que el suyo, y este proceder no promete bonanza en esta ciudad. Es más, sus acciones le causan desgracias, a pesar de conducirse honestamente. De hecho, otros personajes se aprovechan de su buen corazón, porque saben que él es incapaz de negarles un favor. $Y$ es esta enajenación que sufre Karl lo que le permite al narrador criticar a la sociedad neoyorkina, pues por medio de las desaventuras de este personaje, el lector se entera de las condiciones de vida que experimentan los de la clase alta o la clase obrera, sean estos inmigrantes o no.

\subsection{El extrañamiento}

Indudablemente, el extrañamiento que Poeta en Nueva York provoca en los lectores es más que conocido. Sus imágenes surrealistas y en varios casos grotescas, requieren de lo que Neil C.
McKinlay (2001) llama una "deshumanización". A esto se refiere cuando explica que es imposible llegar a una interpretación definitiva de las imágenes que Federico García Lorca fragmentó en sus poemas. La deshumanización se da cuando el lector se olvida de toda lógica y se detiene a apreciar la obra de arte que tiene ante sí, imagen tras imagen, palabra por palabra. Sin embargo, al deshumanizarse el lector (dejando a la razón descansar un rato) comienza a percibir la humanidad de lo que el poeta quiso exponer entre sus versos y, esto es, como ya se mencionó, la decadencia de la sociedad capitalista que se consume a sí misma y a quien ingrese a ella.

Nada lejos anda Franz Kafka de causar enajenación en sus lectores con esta novela incompleta y muy a su estilo. La carencia de empatía en los otros personajes llega al borde de lo risible, y los eventos que vive Karl son absurdos en su mayoría, aunque no al extremo lorquiano del sinsentido. Pero este aspecto de lo absurdo y el misterio causado por la ausencia de uno o varios capítulos hacia el final de la novela es lo que enriquecen al texto. Esa falta de resolución al problema de Karl Rossmann imposibilita al lector decidir la suerte final de este personaje, porque no posee una sola interpretación. Tiene, en cierto grado, esa deshumanización que requiere la lectura de Lorca para simplemente disfrutar la historia, sea que tenga un final feliz aparente, del tipo quijotesco, a causa de la ilusión de no darse por vencido y de seguir "desapareciendo" de las dificultades, como apunta Alí Víquez Jiménez (2012). Sin embargo, si se toma el camino del 'lado oscuro', los dos textos sostienen la interpretación de que estos escritores estaban exponiendo una vida sin esperanza explotada sin piedad por el capitalismo y los poderes autoritarios. Karl fue explotado desde que puso sus pies en tierra firme americana, pues aunque su tío le dio techo, educación y sustento, su vida no estaba exenta de sacrificios y de tareas forzosas (recuérdense sus clases de equitación y de inglés desde tempranísimas horas) y que, al igual que en sus otros empleos, se le pedía obediencia absoluta $y$, al menor descuido de 
sus labores, se le "azotaba" inmisericordemente (como expuso Lorca: “¡azotadlo, hijos míos, azotadlo!’).

\subsection{La percepción del arte de Kafka y de García Lorca}

Un punto más por comparar es la suspicacia que tenían Kafka y García Lorca a la hora de publicar sus obras, aunque por razones diferentes. Es bien conocido que si no fuera por Max Brod, ni esta novela ni buena parte del trabajo literario kafkiano habrían sido internacionalmente conocidos. Kafka seguía un obsesivo y complejo proceso de creación y de re-creación (Payne, 1997), el cual responde a la necesidad siempre insatisfecha que le dejaba el arte. Monica Grosu (2010) considera que la literatura fue para este autor un mecanismo de redención, como una forma de plegaria con la que pudiera reconciliarse con el mundo exterior y exponer la oscuridad de su propio mundo interior. Asimismo, Grosu afirma que Kafka, a través de esta novela, creó una "parábola abierta" que simboliza la ansiedad y la alienación propias del siglo XX.

En el caso de García Lorca, Mario Castro Arenas (2010) afirma que este autor temía a que la edición de sus poemas en libros fuera a 'enterrar' su obra, porque creía que era mejor declamar sus versos al público para que no se perdiera la frescura y el impacto que él buscaba. Además, algunos de los poemas en Poeta en Nueva York podrían haberle causado problemas al escritor si hubieran sido difundidos, ya fuera por su contenido homosexual o por la crítica abierta a la cultura y sociedad estadounidenses. Otra razón que menciona Castro Arenas es que Lorca consideraba su poesía y su dramaturgia como un trabajo en permanente evolución $\mathrm{y}$ si los llegaba a imprimir para que fueran publicados, causaría una ruptura en el proceso creativo. Es determinante cómo estos dos escritores creyeron en un proceso creativo en evolución y en perfeccionamiento, el cual no era justo interrumpir dándoselo a la prensa. Se comprende ahora el recelo que les causaba la imprenta, pues significaba para entrambos la muerte de su creación.

\section{Conclusiones}

Aunando la opinión de Tania RomeroGonzález (2015) con la de este ensayo, García Lorca creó un universo poético muy propio e inconfundible. Este debe ser estudiado desde múltiples ángulos para apreciar con mayor profundidad sus simbolismos y su tajante crítica sociocultural. Franz Kafka, a pesar del pesimismo y la desolación presentes en sus obras, muestra ser un escritor que comprendió el rumbo que estaba tomando el mundo. Se afirma esto porque su América (o El desaparecido, según otras versiones) fue escrita en 1912, unos diecisiete años antes de que Lorca visitara Nueva York y que redactara sus poemas. Llama la atención que las descripciones estudiadas en este ensayo sean tan similares, con detalles tan puntuales que dan la impresión de que los dos escritores estuvieran viendo las mismas imágenes. No hay lugar para sospechar que ellos llegaran alguna vez a verse y mucho menos que Lorca haya leído a Kafka, pues sus muertes y sus publicaciones post mortem lo comprueban.

Federico García Lorca y Franz Kafka parecían no tener nada más que los uniera que el absurdo, muy utilizado luego por los surrealistas. Sin embargo, este ensayo demuestra que si se dejan de lado las particularidades propias de cada uno de estos autores, sus textos, América y Poeta en Nueva York, comparten mucho en común. Se comprobó así que las imágenes de Nueva York fueron descritas desde ángulos semejantes, ya sea desde un balcón, en un alto edificio, o desde las calles mismas, entre la muchedumbre. También criticaron el abusivo capitalismo que explota, por un lado a sus trabajadores, extrayéndoles su humanidad y sus sueños, y por otro, a los animales, víctimas del enriquecimiento a costa de su sangre. Las imágenes grotescas representaron en ambos textos la repulsión que tanto despotismo inhumano les causó a estos escritores. 
Kafka y García Lorca fueron artistas apasionados por su labor, porque en la producción literaria ellos encontraron la satisfacción que el mundo alrededor suyo no les ofrecía. Ellos se tomaron en serio el trabajo de traducir sus vivencias, temores e ilusiones (o más bien desilusiones) en literatura. No fueron escritores preocupados por complacer a un lector con finales felices o con las historias resueltas, sino que su mayor inquietud fue seguir el proceso creativo, evolucionándolo y perfeccionándolo conforme vivieran y sintieran más el dolor humano que les dejaba la enajenación de una sociedad en vías de convertirse en suciedad. Enfrentarse a cada uno de estos escritores es tarea difícil, más aún arriesgarse a compararlos. No solo por su pesimismo y sus imágenes de sufrimiento, enteramente humanos, sino porque cada uno, a su modo, requiere de un lector determinado a encontrar escondidos, bajo tanto símbolo, una interpretación que satisfaga su hambre literaria. No obstante este esfuerzo, vale la pena 'deshumanizarse' para disfrutarlos absurdamente.

\section{Bibliografía}

Bosch, Aurora. 2005. "Convertirse en americanos. Las minorías étnicas y las dos guerras mundiales en Estados Unidos". En: Ayer (58): 229-252. Recuperado de http://www. jstor.org/stable/41328489

Castro Arenas, Mario. 2010. "Poeta en Nueva York de Federico García Lorca". Alicante: Biblioteca Virtual Miguel de Cervantes. Recopilado en http://www. cervantesvirtual.com/nd/ark:/59851/ bmcw95r8

Chaves Bustos, J. Mauricio. 2007. "Federico García Lorca: la voz que no calla -a los 70 años de su asesinato-“. En: Logos, 0 (12): 69-76. Recuperado de http://revistas. lasalle.edu.co/index.php/lo/article/ view/1543
Chevalier, Jean y Alain Gheerbrant. 1986. Diccionario de lo Símbolos (1a ed.). Barcelona: Herder Editorial, S.L.

García Lorca, Federico. 1987. Poeta en Nueva York. Madrid: Ediciones Cátedra.

Grosu, Monica. 2010. “Franz Kafka's America: an Utopia of Liberty". En: Scientific Journal Of Humanistic Studies II (2): 130-133.

Kafka, Franz. 2013. América (Alberto Laurent, Trad.). Barcelona: Ediciones Brontes. (La obra original fue publicada en 1927).

Llera Ruíz, José Antonio. 2011. “Texto, contexto e intertexto en "Paisaje de la multitud que vomita (Anochecer de Coney Island)", de Federico García Lorca". En: 1616: Anuario de Literatura Comparada I: 185-219.

McKinlay, Neil. C. 2001. "The Dehumanisation of Poeta en Nueva York". En: Journal Of Iberian \& Latin American Studies VII (2): 157-171. doi:10.1080/14701840120104827

McMullan, Terrence. 1996. "Federico García Lorca's Poeta en Nueva York and The City of Tomorrow". En: Bulletin Of Hispanic Studies LXXIII (1): 65-79. doi:10.1080/000749096760150024

Millán, María Clementa. 1987. "Introducción: La ciudad". En F. García Lorca, Poeta en Nueva York (págs. 71-78). Madrid: Ediciones Cátedra.

Ortega López, José. 1997. "La ciudad de Nueva York en la Poesía Moderna Norteamericana". En: REDEN: revista española de estudios norteamericanos (14): 55-92. 
Payne, Kenneth. 1997. "Franz Kafka’s America". En: Symposium LI (1): 30-42.

Real Academia Española. (30 de noviembre de 2015). mañana. Obtenido de Diccionario de la lengua española: http://dle.rae. es/?id=OJHi0DU
Romero-González, Tania. 2015. “La regeneración del 27: Poeta en Nueva York y Un chien andalou". En: Rilce XXXI (2): 523-543.

Víquez Jiménez, Alí. 2012. "El desaparecido aparece". En: Filología y Lingüística XXXVIII (1): 97-115.

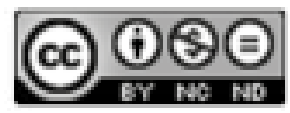

Este obra está bajo una licencia de Creative Commons Reconocimiento-NoComercial-SinObraDerivada 4.0 Internacional. 